\title{
Sustainable Cross-linked Porous Corn Starch Adsorbents with High Methyl Violet Adsorption
}

Huige Wei, ${ }^{1 *}$ Junhui Ma, ${ }^{1}$ Yapeng Shi, ${ }^{1}$ Dapeng Cui, ${ }^{2}$ Mingzhu Liu, ${ }^{3}$ Na Lu, ${ }^{4}$ Ning Wang, ${ }^{5}$ Tingting Wu, ${ }^{6}$ Evan K. Wujcik ${ }^{7}$ and Zhanhu Guo ${ }^{8 *}$

The present paper reported the preparation of cross-linked porous corn starch (c-PCS) with high methyl violet adsorption capability. To obtain c-PCS, the pre-alkalization of porous corn starch (PCS) was first performed using sodium hydroxide/sodium chloride $(\mathrm{NaCl} / \mathrm{NaOH})$, followed by the cross-linking of PCS employing epichlorohydrin $(\mathrm{ECH})$ as the cross-linking reagent. The effects of key experimental parameters, i.e. the mass ratio of $\mathrm{NaOH}$ to PCS $\left(m_{\mathrm{NaOH}} / m_{\mathrm{pcs}}\right)$, the mass ratio of $\mathrm{NaCl}$ to PCS $\left(m_{\mathrm{NaCl}} / m_{\mathrm{pcs}}\right)$, and the temperature $\left(T_{\mathrm{a}}\right)$ and reaction time $\left(t_{\mathrm{a}}\right)$ during the alkalization process, the ratio of ECH volume to the mass of PCS $\left(V_{\mathrm{ECH}} / m_{\mathrm{pcs}}\right)$, the ratio of solution volume to the mass of PCS $\left(V s / m_{\mathrm{pcs}}\right)$, pH value, the temperature $\left(T_{\mathrm{c}}\right)$, and the reaction time $\left(t_{\mathrm{c}}\right)$ in the cross-linking reaction, on the adsorption capability of c-PCS using methyl violet as an adsorbed model were investigated in details. A maximum adsorption capability of $48.3 \%$ was achieved with the following optimum experimental parameters: $m_{\mathrm{NaOH}} / m_{\mathrm{pcs}}=0.02, m_{\mathrm{NaCl}} / m_{\mathrm{pcs}}=0.06, T_{\mathrm{a}}=40{ }^{\circ} \mathrm{C}, t_{\mathrm{a}}=1.0 \mathrm{~h}, V_{\mathrm{ECH}} / m_{\mathrm{pcs}}=0.003(\mathrm{~mL} / \mathrm{g}), V / m_{\mathrm{pcs}}=7(\mathrm{~mL} / \mathrm{g}), \mathrm{pH}=10, T_{\mathrm{c}}=20$ ${ }^{\circ} \mathrm{C}, t_{c}=3.0 \mathrm{~h}$. The improved adsorption performance was caused by the changed morphology as confirmed by the scanning electron microscope image.

Keywords: Porous corn starch; Cross-Linking; Adsorbents

Received 1 October 2018, Accepted 7 November 2018

DOI: $10.30919 / \mathrm{esmm} 5 \mathrm{f} 162$

\section{Introduction}

As a natural polymer, starch has attracted extensive research attention due to its wide availability, low cost, eco-friendliness, and renewability. ${ }^{1}$ Starch-based sustainable biomaterials, ${ }^{2}$ self-healing composites, ${ }^{3}$ shape memory materials, ${ }^{4}$ etc. have been widely investigated. Unfortunately,

${ }^{1}$ College of Chemical Engineering and Materials Science Tianjin University of Science and Technology, Tianjin, 300457 China

${ }^{2}$ College of Packing and Printing Engineering Tianjin University of Science and Technology, Tianjin, 300222 China

${ }^{3}$ Department of Chemistry and State Key Laboratory of Applied Organic Chemistry

Lanzhou University, Lanzhou, 730000 China

${ }^{4}$ Lyles School of Civil Engineering, School of Materials Engineering, Birck Nanotechnology Center, Purdue University, West Lafayette, 47906, USA

${ }^{5}$ State Key Laboratory of Marine Resource Utilization in South China Sea, College of Materials and Chemical Engineering, Hainan University, Haikou 570228, PR China

${ }^{6}$ Department of Civil and Environmental Engineering, The University of Alabama in Huntsville, Huntsville, Alabama 35899, USA

${ }^{7}$ Materials Engineering and Nanosensor [MEAN] Laboratory, Department of Chemical and Biological Engineering, University of Alabama, Tuscaloosa, AL, USA

${ }^{8}$ Integrated Composites Laboratory (ICL), Department of Chemical \& Biomolecular Engineering, University of Tennessee, Knoxville, TN 37996 USA

*E-mail: huigewei@tust.edu.cn; zguo10@utk.edu the inherent limitations of native starch (e.g. rather small surface area and pore volume, low shear resistance, and high susceptibility to thermal decomposition) restrict its deployment for practical applications. ${ }^{5-7}$ The modification of native starches, therefore, has become a popular approach to achieving desirable physicochemical characteristics and to extending their application scope. ${ }^{8-11}$ In the midst of various types of modified starch, porous starch has attracted increasing attention recently because of its unique pore structure and rich pores. ${ }^{12-15}$ Till now, porous starch has been explored as microcapsules or adsorbents for versatile applications, e.g. in the fields of food, ${ }^{16}$ medicine, ${ }^{17}$ environmental remediation, ${ }^{18,19}$ cosmetics, ${ }^{20}$ and so forth.

The history of porous starch dates back to 1957. Under the transmission electron microscope, Professor Whistler in Purdue University, USA, and another Japanese scientist observed rich pores extending from the surface to the inner core in the corn starch which was hydrolyzed by $\alpha$-amylase. ${ }^{21}$ In 1984, the concept of "Aperture Starch" was first proposed by Whistler in his book of Starch: Chemistry and Technology. ${ }^{1}$ Later in 1997, Ishii gave this type of modified corn another term-porous starch, which has been used till today.

Up to now, a variety of approaches have been developed to produce porous starch, including freezing-solvent exchange technique, ${ }^{22}$ microwave processing, ${ }^{23}$ ultrasonic treatment, ${ }^{24}$ acid treatment, ${ }^{25}$ and enzymatic hydrolysis. ${ }^{26,27}$ Particularly, enzymatic hydrolysis of native starch using $\alpha$-amylase or glucoamylase at sub-gelatinization temperature has been commonly employed for the main advantage of low energy cost. Recent study indicated that porous starch with higher hydrolysis efficiency could be yielded by conjugating the endo-activity 
of $\alpha$-amylase and the exo-activity glucoamylase. ${ }^{28}$ Porous corn starch (PCS) used for adsorbents had also been successfully prepared using a mixture of $\alpha$-amylase and glucoamylase. ${ }^{29}$ The PCS exhibited better adsorption performance than native corn starch. Yet, there is still a concern for the structure durability of the as-obtained PCS. Porous starch granules usually become very fragile after the enzymatic hydrolysis, and are easy to rupture and therefore lose the adsorption capability when they are subjected to freeze-thaw cycles. ${ }^{30}$

To obtain adsorbents with enhanced structure stability, the crosslinking of PCS was carried out in the present study, where PCS was pre-alkalized first using sodium hydroxide/sodium chloride $(\mathrm{NaCl} / \mathrm{NaOH})$, and then cross-linked employing epichlorohydrin $(\mathrm{ECH})$ as the cross-linking reagent. The cross-linking was reported to stabilize and strengthen the starch by adding random intra- or inter-covalent bonds in the starch. ${ }^{30,31}$ Moreover, the cross-linking is expected to bring about rougher granular surface, which is beneficial for the adsorption and immobilization of small molecular adsorbates. Nevertheless, the cross-linking must be carried out with care since overdue cross-linking would greatly reduce the specific surface area of the porous starch and thus lead to inferior adsorption performance. Optimum experimental parameters are therefore key to achieving cross-linked porous corn starch (c-PCS) with both robust structure and high adsorption capability. To this end, the effects of experimental parameters, namely, the mass ratio of $\mathrm{NaCl}$ to PCS $\left(m_{\mathrm{NaCl}} / m_{\mathrm{pce}}\right)$, the mass ratio of $\mathrm{NaOH}$ to PCS $\left(m_{\mathrm{NaOH}} / m_{\mathrm{pcs}}\right)$, the temperature $\left(T_{\mathrm{a}}\right)$ and time $\left(t_{\mathrm{a}}\right)$ during the alkalization reaction, the ratio of ECH volume to the mass of PCS $\left(V_{\mathrm{ECH}} / m_{\mathrm{pcs}}\right)$, the ratio of solution volume to the mass of PCS $\left(V_{s} / m_{\mathrm{pcs}}\right), \mathrm{pH}$ value, the temperature $\left(T_{\mathrm{c}}\right)$ and time $\left(t_{\mathrm{c}}\right)$ during the cross-linking reaction, on the adsorption capability of c-PSC using methyl violet as an adsorbed model were investigated in details. The chemical structure and the morphology of c-PCS were also studied to unveil the behind mechanism governing the enhanced adsorption performance.

\section{Materials}

$\mathrm{NaCl}$ and citric acid were provided by Tianjin Kwangfu Fine Chemical Industry Research Institute (Tianjin, China). ECH and sodium dihydrogen phosphate were purchased from Tianjin Chemical Reagent Co., Ltd. (Tianjin, China), hydrochloric acid (chemically pure) was supplied by Baiyin Liangyou Chemical Reagent Company (Gansu, China). Corn starch (food grade) was purchased from Xuejing Biochemical Co. Ltd. (Gansu, China). Both $\alpha$-Amylase (biochemical grade) with an activity of 3.7 units/mg and glucoamylase (biochemical grade) with an activity of 100 units/mg were provided by Aoboxing Biotechnology Co., Ltd. (Beijing, China). Methyl violet was supplied by Tianxin Chemical Company (Tianjin, China). $\mathrm{NaOH}$ was purchased from Shuangshuang Chemical Industry Co., Ltd. (Shandong, China). All the other chemicals were analytical reagent grade and were used asreceived unless otherwise noted.

\subsection{Preparation of porous corn starch (PCS)}

The PCS was prepared by the enzymatic modification of native corn starch by a mixture of $\alpha$-amylase and glucoamylase as described in our previous paper. ${ }^{29}$ Briefly, the corn starch was added to citric acid-disodium hydrogen phosphate buffer solution ( $\mathrm{pH}$ was 5.5) in a round-bottomed flask. The ratio of the liquid volume to the mass of the corn starch was $8: 1(\mathrm{~mL} / \mathrm{g})$. The mixture was heated using water bath to $50{ }^{\circ} \mathrm{C}$ under magnetic stirring, and then $\alpha$-amylase and glucoamylase ( $\left.m_{\text {a-anylase }}: m_{\text {glucoanylase }}=6: 1\right)$ were added. The mass ratio of the enzymes (including $\alpha$-amylase and glucoamylase) to the native corn starch was 0.02:1.00. After $12 \mathrm{~h}, 0.1 \mathrm{M} \mathrm{NaOH}$ solution was added to the reaction solution to adjust the $\mathrm{pH}$ to 10 to terminate the reaction. Then the solution was filtered and the product was rinsed with distilled water for several times. The obtained PCS was dried at room temperature and grinded for further use.

\subsection{Preparation of cross-linked porous corn starch (c-PCS)}

ECH was employed as the cross-linking reagents for PCS. Specifically, appropriate amounts of $\mathrm{NaOH}, \mathrm{NaCl}$, and distilled water were added to $100 \mathrm{~mL}$ round-bottomed flask, and then the magnetic stirring was applied to form a clear solution (denoted as solution A). Solution A was heated by water bath to a preset temperature, and then the as-prepared PCS was added for the alkalization. The corresponding solution was denoted as solution $\mathrm{B}$.

The cross-linking reaction was carried out after the alkalization process. $\mathrm{NaOH}$ or hydrochloric acid was first used to manipulate $\mathrm{pH}$ value of $\mathrm{B}$. ECH was then injected slowly to $\mathrm{B}$. When the cross-linking reaction was terminated, hydrochloric acid was added to the flask to tune $\mathrm{pH}$ value to neutral. The solution was filtered and the product was rinsed with distill water for several times. The obtained c-PCS was dried at room temperature and milled for future characterizations.

\subsection{Characterizations}

\subsubsection{Fourier transform infrared spectroscopy (FTIR)}

Fourier transform infrared spectroscopy (FTIR) of the c-PSC was performed on a FTIR spectrophotometer (American Nicolet Corp., Model 170-SX). About $40 \mathrm{mg}$ blend of c-PSC and solid $\mathrm{KBr}$ powder was used to prepare a pellet. The pellet was dried and then exposed to FTIR spectrophotometry. Transmittances were recorded at a wavenumber ranging from 4000 to $500 \mathrm{~cm}^{-1}$.

\subsubsection{Scanning electron microscopy (SEM)}

The microstructure of the samples was observed using a scanning electron microscope (JEOL JSM-6701F SEM). The samples were coated with gold prior to the observation.

\subsubsection{Adsorption capability evaluation}

$1.5 \mathrm{~g}$ c-PCS was added to $50.00 \mathrm{~mL}$ methyl violet solution in water $(0.06 \mathrm{~g} / \mathrm{L})$ and stirred for $5 \mathrm{~h}$ at room temperature for a complete adsorption. Then the suspension was centrifuged at 10,000 rpm for 10 min, and the supernatant was collected. The concentration of the methyl violet in the supernatant was determined by the absorbance intensity at $583 \mathrm{~nm}$ using a UV/Vis spectroscopy (Lambda 35, Perkin Elmer Corp., USA). The adsorption ratio $(A R)$ was calculated using Eq. (1):

$$
A R=\frac{C_{0}-C_{1}}{C_{0}} \times 100 \%
$$

where $C_{0}$ and $C_{1}$ represent the concentration of methyl violet in the original solution and in the supernatant, respectively. In the present study, the value of $C_{0}$ was $0.06 \mathrm{~g} / \mathrm{L}$.

\section{Results and discussions}

\subsection{Optimization of experimental parameters}

To obtain c-PCS with optimum adsorption capacity, the effect of experimental parameters including $m_{\mathrm{NaOH}} / m_{\mathrm{pcs}}, m_{\mathrm{NaCl}} / m_{\mathrm{pcss}}, T_{\mathrm{a}}$ and $t_{\mathrm{a}}$ during the alkalization reaction, $V_{\mathrm{ECH}} / m_{\mathrm{pcs}}, V_{\mathrm{s}} / m_{\mathrm{pcs}}, \mathrm{pH}$ value, $T_{\mathrm{c}}$, and $t_{\mathrm{c}}$ during the cross-linking reaction, on the adsorption behaviors was investigated. 


\subsubsection{Effect of alkalization reaction parameters on the adsorption ratio}

\subsubsection{The mass ratio of $\mathrm{NaOH}$ to PCS $\left(m_{\mathrm{NaOH}} / m_{p c}\right)$}

To enhance the reactivity of PCS with ECH, alkalization was performed using $\mathrm{NaOH}$. The hydroxyl groups of starch molecules reacted with $\mathrm{NaOH}$ and yielded sodium salt (Eq. (2)). ${ }^{32}$ Unfortunately, $\mathrm{NaOH}$ and other alkalies are also able to induce the gelatinization of starch even at moderate temperatures. ${ }^{33,34}$ The intermolecular hydrogen bonds between starch molecules are interrupted by alkalies. Correspondingly, the starch structure begins to loosen and therefore is penetrated by water molecules. The hydrophilic starch molecules are surrounded by water molecules, become hydrated and swollen. As a result, the starch molecules are dissolved in water, a process referred to gelatinization. The gelatinization makes the alkalization reaction difficult to proceed and thus is expected to bring about a reduced adsorption performance. In order to prevent the gelatinization, $\mathrm{NaCl}$ was added in the experiment. $\mathrm{NaCl}$ was reported to compete for water against starch and reduce the water activity $\left(\alpha_{\mathrm{w}}\right)$. The ionic interaction between sodium ions and starch polymers reduced the plasticizing effect of water and therefore was able to inhibit the gelatinization or to increase the gelatinization temperature. ${ }^{35,36}$

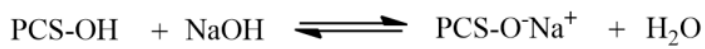

Fig. 1a shows the relationship between $m_{\mathrm{NaOH}} / m_{\mathrm{pcs}}$ and the adsorption ratio with the aid of $\mathrm{NaCl}$ when other experimental parameters were kept constant $\left(m_{\mathrm{NaCl}} / m_{\mathrm{pcs}}=0.06, T_{\mathrm{a}}=30{ }^{\circ} \mathrm{C}, t_{\mathrm{a}}=2.0 \mathrm{~h}\right.$, $V_{\mathrm{ECH}} / m_{\mathrm{pcs}}=0.001(\mathrm{~mL} / \mathrm{g}), V_{\mathrm{s}} / m_{\mathrm{pcs}}=6(\mathrm{~mL} / \mathrm{g}), \mathrm{pH}=9, T_{\mathrm{c}}=30{ }^{\circ} \mathrm{C}, t_{c}=2.0$ h). It is observed that the adsorption ratio initially increases with increasing the $m_{\text {NaOH }} / m_{\text {pcs }}$ until a maximum value is reached and then begins to decrease with further increasing the $m_{\mathrm{NaOH}} / m_{\mathrm{pcc}}$. This phenomenon is explained that at low values of $m_{\mathrm{NaOH}} / m_{\mathrm{pcs}}(\leq 0.02), \mathrm{NaCl}$ was still capable of preventing the gelatinization, and therefore further increasing the mass ratio of $\mathrm{NaOH}$ to PCS was beneficial for the alkalization reaction and thus for higher adsorption ratios. Nevertheless, part of gelatinization began to occur when further increasing the amount of $\mathrm{NaOH}$ considering the limited inhibitory effect of $\mathrm{NaCl}$ at a constant concentration $\left(m_{\mathrm{NaCl}} / m_{\mathrm{pcs}}=0.06\right)$, and correspondingly the adsorption ratio was reduced. Complete gelatinization was observed when high loadings of $\mathrm{NaOH}$ were used, rendering the following cross-linking reaction completely impossible. Therefore, the optimum $m_{\mathrm{NaCl}} / m_{\mathrm{pcs}}$ as suggested by Fig. 1a is 0.02 .
3.1.1.2 The mass ratio of $\mathrm{NaCl}$ to $\mathrm{PCS}\left(\mathrm{m}_{\mathrm{NaC}} / m_{p c}\right)$

As aforementioned, $\mathrm{NaCl}$ functioned to prevent the gelatinization or to increase the gelatinization temperature of starch during the alkalization process. To investigate the optimum amount of $\mathrm{NaCl}$ required for the alkalization reaction, the adsorption ratio as a function of $m_{\text {Nacl }} / m_{\text {pcs }}$ was plotted while keeping other parameters constant $\left(m_{\mathrm{NaOH}} / m_{\mathrm{pcs}}=0.02, T_{\mathrm{a}}=\right.$ $30{ }^{\circ} \mathrm{C}, t_{\mathrm{a}}=2.0 \mathrm{~h}, V_{\mathrm{ECH}} / m_{\mathrm{pcs}}=0.001(\mathrm{~mL} / \mathrm{g}), V_{\mathrm{s}} / m_{\mathrm{pcs}}=6(\mathrm{~mL} / \mathrm{g}), \mathrm{pH}=9, T_{\mathrm{c}}$ $\left.=30{ }^{\circ} \mathrm{C}, t_{c}=2.0 \mathrm{~h}\right)$. As indicated by Fig. $1 \mathrm{~b}, \mathrm{NaCl}$ was effective to increase the adsorption ratio at low values of $m_{\mathrm{Nacl}} / m_{\mathrm{pcs}}$. It is worthy of note that when $m_{\mathrm{Nac}} / m_{\mathrm{pcs}}$ reaches 0.06 , it is useless further increasing the amount of $\mathrm{NaCl}$, and the adsorption ratio begins to level off. Thus, it can be inferred that an optimum $m_{\mathrm{NaCl}} / m_{\mathrm{pcs}}$ for the alkalization is 0.06 .

\subsubsection{The alkalization temperature $\left(T_{d}\right)$}

Fig. 2a depicts the effect of $T_{\mathrm{a}}$ on the adsorption ratio of methyl violet (the other parameters: $m_{\mathrm{NaOH}} / m_{\mathrm{pcs}}=0.02, m_{\mathrm{NaCl}} / m_{\mathrm{pcs}}=0.06, t_{\mathrm{a}}=2.0 \mathrm{~h}$, $V_{\mathrm{ECH}} / m_{\mathrm{pcs}}=0.001(\mathrm{~mL} / \mathrm{g}), V_{\mathrm{s}} / m_{\mathrm{pcs}}=6(\mathrm{~mL} / \mathrm{g}), \mathrm{pH}=9, T_{\mathrm{c}}=30{ }^{\circ} \mathrm{C}, t_{c}=2.0$ h). At lower temperatures $\left(\leq 40{ }^{\circ} \mathrm{C}\right)$, the adsorption ratio increases with increasing the $T_{\mathrm{a}}$. In the temperature range of 40 to $50{ }^{\circ} \mathrm{C}$, a short plateau occurs, and then the adsorption ratio decreases when $T_{\mathrm{a}} \geq 50{ }^{\circ} \mathrm{C}$. This phenomenon is explained by two competing effects brought by the increased temperature. On one hand, the reaction rate increases with increasing the temperature, according to Arrhenius Equation (Eq. (3)).

$$
k=A e^{-E_{a} / R T}
$$

where $k$ is the rate constant, $T$ is the absolute temperature in $\mathrm{K}, A$ is the pre-exponential factor, $E_{\mathrm{a}}$ is the activation energy for the reaction in $\mathrm{J}$, and $R$ is the universal gas constant in $\mathrm{J} / \mathrm{molK}$. Thus the alkalization of PCS took place more completely during the reaction and therefore guaranteed a higher adsorption ratio. On the other hand, the PCS was prone to gelatinization at higher temperatures. ${ }^{37}$ When alkalization temperatures were lower than $40{ }^{\circ} \mathrm{C}$, the positive effect of increasing the temperature dominated, and the gelatinization was still under control with the aid of $\mathrm{NaCl}$; the positive and negative effects began to balance out at temperatures ranging from 40 to $50{ }^{\circ} \mathrm{C}$. When further increase the temperature, serious gelatinization dominated, and thus the adsorption ratio was decreased. An optimum alkalization temperature of $40{ }^{\circ} \mathrm{C}$ is therefore determined from Fig. 2a.

\subsubsection{The alkalization time $(t)$}
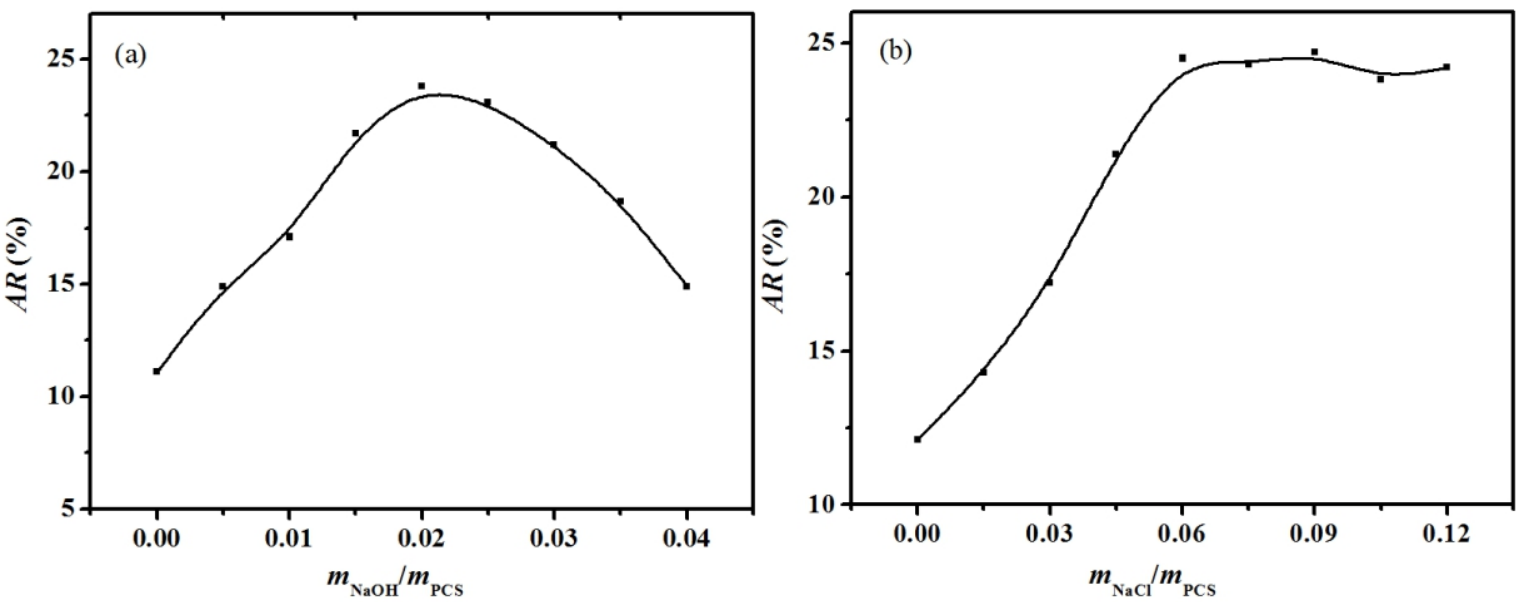

Fig. 1 The effect of (a) $m_{\mathrm{NaOH}} / m_{\mathrm{pcs}}$ and (b) $m_{\mathrm{NaCl}} / m_{\mathrm{pcs}}$ on the adsorption ratio of methyl violet. 
The influence of alkalization time $t_{\mathrm{a}}$ on the adsorption ratio was investigated in Fig. 2b while keeping the other parameters constant: $m_{\text {NaOH }} / m_{\text {pcs }}=0.02, m_{\text {Nacl }} / m_{\mathrm{pcs}}=0.06, T_{\mathrm{a}}=40{ }^{\circ} \mathrm{C}, V_{\mathrm{ECH}} / m_{\mathrm{pcs}}=0.001(\mathrm{~mL} / \mathrm{g})$, $V / m_{\mathrm{pcs}}=6(\mathrm{~mL} / \mathrm{g}), \mathrm{pH}=9, T_{\mathrm{c}}=30^{\circ} \mathrm{C}, t_{c}=2.0 \mathrm{~h}$. As shown in Fig. $2 \mathrm{~b}$, the adsorption ratio first increases with increasing the reaction time, but then decreases slowly. It is reasonable that enough time is required to activate the starch molecules in the alkalization process. Nevertheless, it is no use to prolong the reaction time if the alkalization of the starch molecules is completed. Moreover, undesirable gelatinization occurred at prolonged reaction time. Therefore, an optimum alkalization time of $1.0 \mathrm{~h}$ could be confirmed by Fig. $2 \mathrm{~b}$.

\subsubsection{Effect of cross-linking reaction parameters on the adsorption ratio 3.1.2.1 The ratio of ECH volume to the mass of PCS $\left(V_{E C H} / m_{p c}\right)$}

$\mathrm{ECH}$ has long been employed for the crosslinking of polysaccharides. ${ }^{38}$ After the alkalization of PCS (Eq. (4)), the sodium salt of starch reacted with ECH to yield corn starch-epoxy (reaction 2). Diether bridges were formed when corn starch-epoxy further reacted with the hydroxyl groups of another PCS molecule (Eq. (5)). The crosslinking was conducted under heterogeneous conditions where the solid PCS granules reacted with the liquid phase containing $\mathrm{NaOH} / \mathrm{NaCl}$ and $\mathrm{ECH}^{39}$

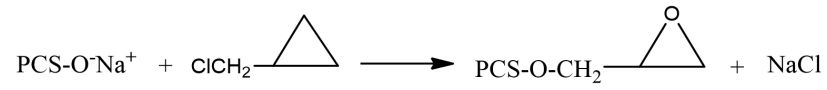

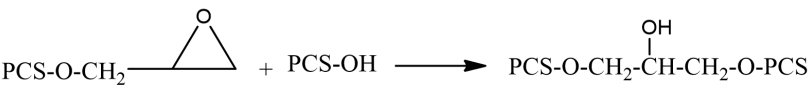

The plot of $V_{\mathrm{ECH}} / m_{\mathrm{pcs}}$ against the adsorption ratio of methyl violet is presented in Fig. 3a (the other experimental parameters: $m_{\mathrm{NaOH}} / m_{\mathrm{pcs}}=$ $0.02, m_{\mathrm{NaCl}} / m_{\mathrm{pcs}}=0.06, T_{\mathrm{a}}=40{ }^{\circ} \mathrm{C}, t_{\mathrm{a}}=1.0 \mathrm{~h}, V / m_{\mathrm{pcs}}=6(\mathrm{~mL} / \mathrm{g}), \mathrm{pH}=9$, $T_{\mathrm{c}}=30{ }^{\circ} \mathrm{C}, t_{c}=2.0 \mathrm{~h}$ ). It is observed that the adsorption ratio initially increases rapidly with increasing the volume of epoxy, and remains relatively constant, and then decreases slowly. The reason is that when little amount of ECH was added, e.g. $V_{\mathrm{ECH}} / m_{\mathrm{pcs}}$ was $0.0005 \mathrm{ml} / \mathrm{g}$, the cross-linking degree of PSC was negligible; therefore, the obtained cPSC exhibited poor adsorption performance. With increasing the amount of epoxy propane, both the surface and the core of the PCS began to be cross-linked. The cross-linking not only stabilizes the structure of PSC and makes the adsorbed methyl violet more stable, but also makes the surface becomes rougher, which is beneficial for the adsorption. ${ }^{30}$ As a result, a significant increase in the adsorption ratio was observed at first. However, when $V_{\mathrm{ECH}} / m_{\mathrm{pcs}}$ was higher than 0.003 $\mathrm{ml} / \mathrm{g}$, overdue cross-linking took place, which might reduce the total
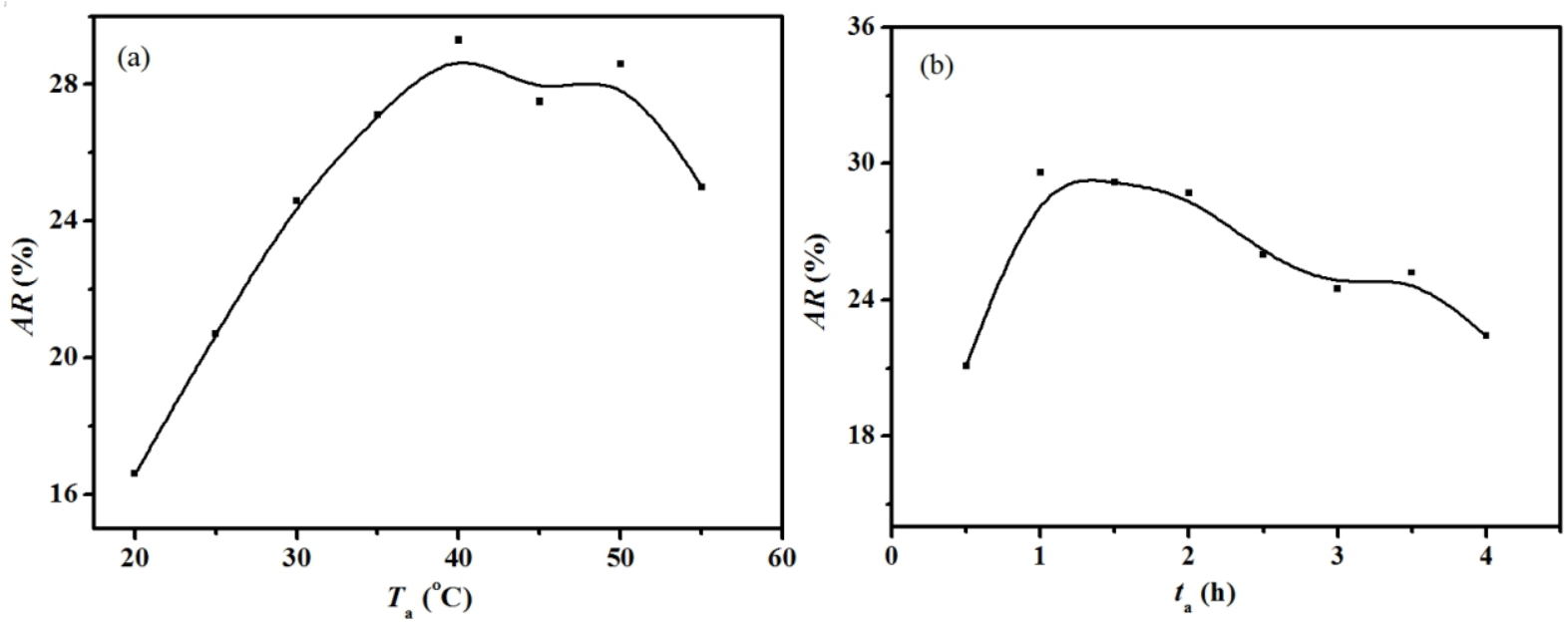

Fig. 2 The effect of (a) $T_{\mathrm{a}}$ and (b) $t_{\mathrm{a}}$ on the adsorption ratio of methyl violet.
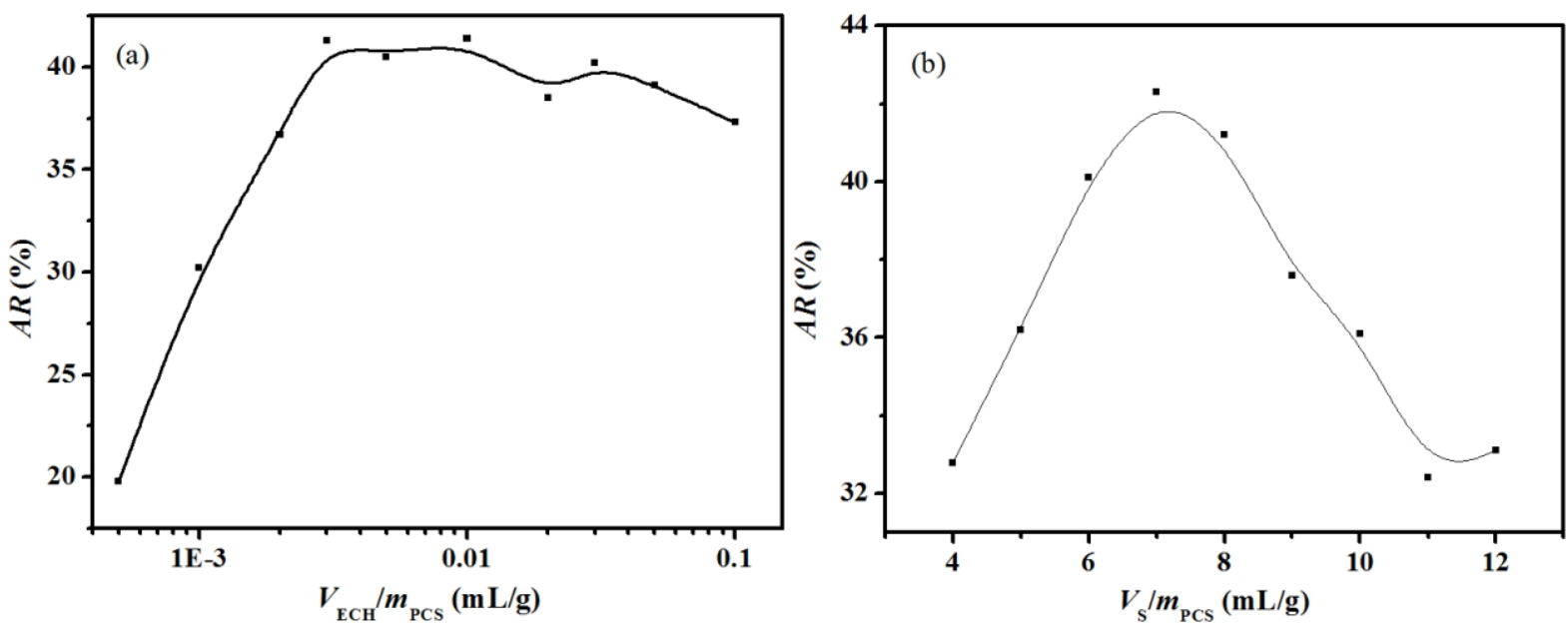

Fig. 3 The effect of (a) $V_{\mathrm{ECH}} / m_{\mathrm{pcs}}$ and (b) $V_{\mathrm{s}} / m_{\mathrm{pcs}}$ on the adsorption ratio of methyl violet. 
pore volume, and thus gave rise to a decreased adsorption ratio. The optimum $V_{\mathrm{ECH}} / m_{\mathrm{pcs}}$ is determined to be $0.003 \mathrm{~mL} / \mathrm{g}$.

\subsubsection{The ratio of solution volume to the mass of PCS $\left(V_{s} / m_{p c s}\right)$}

While keeping other experimental parameters fixed $\left(m_{\mathrm{NaOH}} / m_{\mathrm{pcs}}=0.02\right.$, $m_{\text {NaCl }} / m_{\text {pcs }}=0.06, T_{\mathrm{a}}=40{ }^{\circ} \mathrm{C}, t_{\mathrm{a}}=1.0 \mathrm{~h}, V_{\mathrm{ECH}} / m_{\mathrm{pcs}}=0.003(\mathrm{~mL} / \mathrm{g}), \mathrm{pH}=9$, $T_{\mathrm{c}}=30{ }^{\circ} \mathrm{C}, t_{c}=2.0 \mathrm{~h}$ ), the dependence of adsorption ratio on $V / m_{\mathrm{scs}}$ was studied and plotted in Fig. 3b. In the present study, $V_{s} / m_{\text {pcs }}$ was tuned by distilled water. The parabola going upwards represents two extreme conditions. Under one extreme condition, when the value of $V_{\mathrm{ECH}} / m_{\mathrm{pcs}}$ was very small, that is, very little solvent in the system, poor dispersion of PCS was expected, and thus there was fewer collision chances between the corn molecules and the cross-linking agent. Meanwhile, too little solvent meant highly concentrated $\mathrm{NaOH}$ solutions, which led to the gelatinization of PCS. Under the other extreme condition, when the value of $V / m_{\text {pcs }}$ was very high, i.e. too much solvent in the system, both $\mathrm{ECH}$ and $\mathrm{NaOH}$ were highly diluted, which was not favorable for either the cross-linking reaction or the alkalization. Therefore, an appropriate $V_{\mathrm{s}} / m_{\mathrm{pcs}}$ is required to obtain an optimum adsorption ratio. From Fig. 3b, the optimum $V_{\mathrm{s}} / m_{\mathrm{pcs}}$ of $7(\mathrm{~mL} / \mathrm{g})$ is confirmed.

\subsubsection{3 $\mathrm{pH}$ value}

The plot of $\mathrm{pH}$ value against the adsorption ratio is shown in Fig. 4 (other experimental parameters: $m_{\mathrm{NaOH}} / m_{\mathrm{pcs}}=0.02, m_{\mathrm{NaCl}} / m_{\mathrm{pcs}}=0.06, T_{\mathrm{a}}=$ $40{ }^{\circ} \mathrm{C}, t_{\mathrm{a}}=1.0 \mathrm{~h}, V_{\mathrm{ECH}} / m_{\mathrm{pcs}}=0.003(\mathrm{~mL} / \mathrm{g}), V_{\mathrm{s}} / m_{\mathrm{pcs}}=7(\mathrm{~mL} / \mathrm{g}), T_{\mathrm{c}}=30{ }^{\circ} \mathrm{C}$, $t_{c}=2.0 \mathrm{~h}$ ). It is well known that ECH only has a higher reactivity in the acid or base environment. Therefore, in the beginning of the curve in Fig. 4, the adsorption ratio is very low (e.g. $24.3 \%$ ) since almost no cross-linking reaction occurs at a $\mathrm{pH}$ value of 7 . With increasing the $\mathrm{pH}$ value, ring-open reaction of ECH began to occur and reacted with PCS to form c-PCS. As a result, the adsorption was found to increase with increasing the $\mathrm{pH}$ value in the beginning. Unfortunately, ECH molecules are prone to react with each other or with water molecules at $\mathrm{pH}$ values higher than 10.0. Besides, high $\mathrm{pH}$ values were favorable for the gelatinization. Therefore, the adsorption ration decreased rapidly with increasing the $\mathrm{pH}$ value later. The optimum $\mathrm{pH}$ value is determined to be 10 .

\subsubsection{The cross-linking temperature $(T)$}

Fig. 5a displays the effect of $T_{\mathrm{c}}$ on the adsorption ratio (other experimental parameters: $m_{\text {NaOH }} / m_{\text {pcs }}=0.02, m_{\text {NaCl }} / m_{\text {pcs }}=0.06, T_{\mathrm{a}}=40{ }^{\circ} \mathrm{C}, t_{\mathrm{a}}$

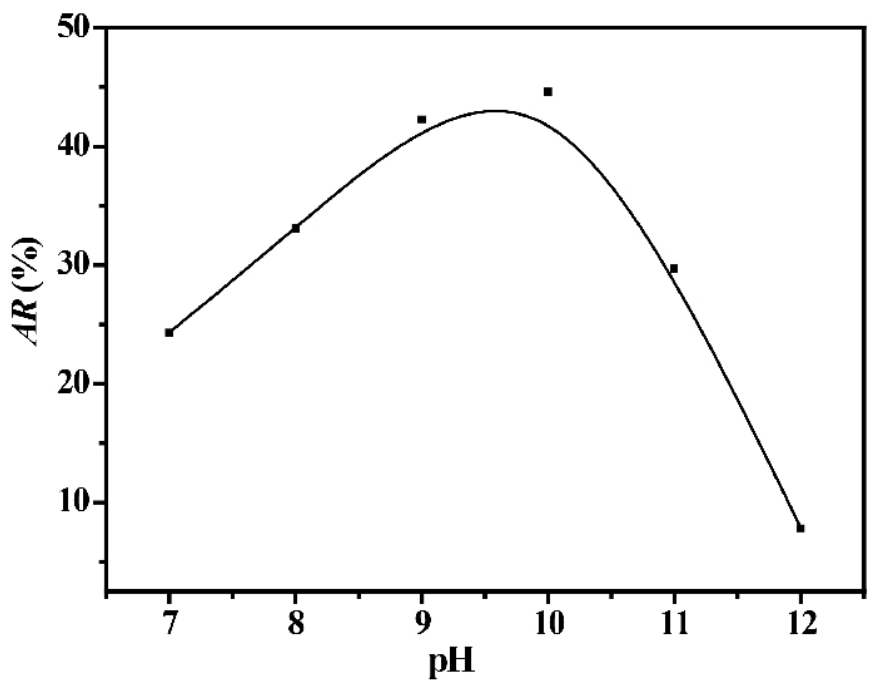

Fig. 4 The effect of $\mathrm{pH}$ value on the adsorption ratio of methyl violet.

$\left.=1.0 \mathrm{~h}, V_{\mathrm{ECH}} / m_{\mathrm{pcs}}=0.003(\mathrm{~mL} / \mathrm{g}), V_{\mathrm{s}} / m_{\mathrm{pcs}}=7(\mathrm{~mL} / \mathrm{g}), \mathrm{pH}=10, t_{c}=2.0 \mathrm{~h}\right)$. It is obvious that increasing $T_{\mathrm{c}}$ is not in favor of high adsorption ratio. The adsorption ratio initially decreases slowly but then rapidly with increasing the $T_{\mathrm{c}}$. The reason is that even though high temperature was good for the reaction rate, it also brought about side reactions of $\mathrm{ECH}$. $\mathrm{ECH}$ would be decomposed, or reacted with each other, or reacted with water molecules, and therefore gave rise to decreased cross-linking degrees. Moreover, the pristine PCS was very fragile, and the additional reaction sites caused by the alkalization made them very sensitive to cross-linking temperatures. PCS ruptured very easily at high temperatures, for example, at a $T_{\mathrm{c}}$ of $65^{\circ} \mathrm{C}$ (Fig. S1 in the supporting information), resulting in sharply reduced adsorption capability. Therefore, $20{ }^{\circ} \mathrm{C}$ is determined to be the optimum $T_{\mathrm{c}}$.

\subsubsection{The cross-linking time ( $t$ )}

The plot of cross-linking time $t_{\mathrm{c}}$ against the adsorption ratio is shown in Fig. $5 \mathrm{~b}$ (other experimental parameters: $m_{\mathrm{NaOH}} / m_{\mathrm{pcs}}=0.020, m_{\mathrm{NaCl}} / m_{\mathrm{pcs}}=$ $0.06, T_{\mathrm{a}}=40{ }^{\circ} \mathrm{C}, t_{\mathrm{a}}=1.0 \mathrm{~h}, V_{\mathrm{ECH}} / m_{\mathrm{pcs}}=0.003(\mathrm{~mL} / \mathrm{g}), V_{\mathrm{s}} / m_{\mathrm{pcs}}=7(\mathrm{~mL} / \mathrm{g})$, $\mathrm{pH}=10, T_{c}=20{ }^{\circ} \mathrm{C}$ ). Adequate time is key to obtaining a considerable cross-linking degree since ECH is a slow-acting cross-linking agent,40 which explains the initial sharp increase of the adsorption ratio with
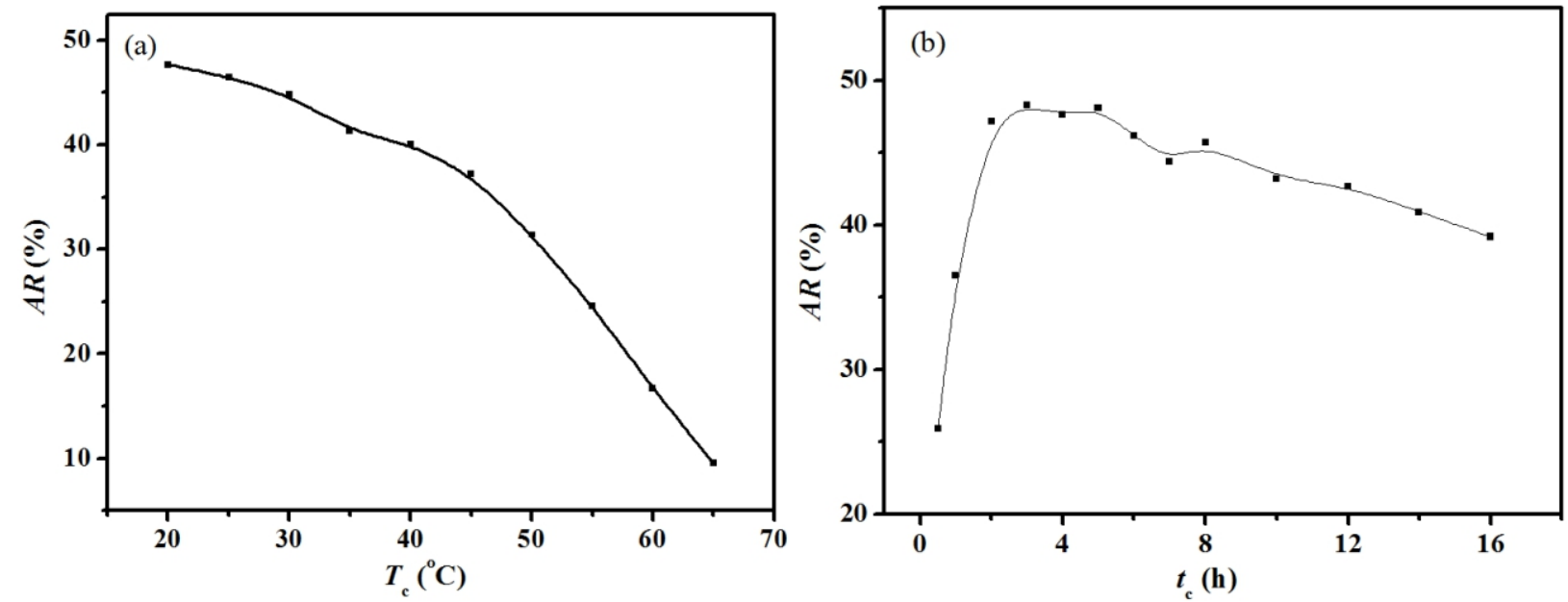

Fig. 5 The effect of (a) $T_{\mathrm{c}}$ and (b) $t_{\mathrm{c}}$ on the adsorption ratio of methyl violet. 
increasing the $t_{\mathrm{c}}$ from 0.5 to $3.0 \mathrm{~h}$ in the curve. Nevertheless, the effect of $t_{\mathrm{c}}$ is not significant any more as long as the cross-linking reaction is complete given long enough reaction time; therefore, a plateau occurs in the $t_{\mathrm{c}}$ range of 3.0 to $5.0 \mathrm{~h}$. Moreover, serious hydrolysis of PCS occurred in the experiment when $t_{\mathrm{c}}$ was further prolonged, e.g. from 5.0 to $16.0 \mathrm{~h}$, which damaged the granular structure of PCS. Meanwhile, the fracture of the PCS molecule chain arose when subjected to continuous shearing force, which also did harm to the integration of the PCS structure, for example, at a $t_{\mathrm{c}}$ of $16.0 \mathrm{~h}$ (Fig. S2 in the supporting information). Therefore, a slow decrease of the adsorption ratio with the increase of $t_{\mathrm{c}}$ is observed (Fig. 5b). An optimal $t_{\mathrm{c}}$ of $3.0 \mathrm{~h}$ is determined.

\subsection{Structure and Morphology}

\subsubsection{FTIR}

Fig. 6 shows the FTIR spectra of (a) pristine corn starch, (b) PCS and (c) c-PCS. Due to the fact that the formed ether bonds during the crosslinking are very similar to those of native corn starch and PCS, no noticeable changes in the characteristic peaks are observed in the spectra of c-PCS. The peaks at 3392, 2927, and $1646 \mathrm{~cm}^{-1}$ correspond to the stretching vibration of $-\mathrm{OH}$, the stretching vibration of $-\mathrm{CH}$, and the bending vibration of $-\mathrm{OH}$... $\mathrm{O}-$ formed between PCS molecules, respectively. ${ }^{41}$ The adsorption bands in the range of 1415 to $1367 \mathrm{~cm}^{-1}$ are assigned to the bending vibration of $-\mathrm{CH}^{30}$ and the typical starch spectra from 1160 to $1013 \mathrm{~cm}^{-1}$ remain relatively unchanged. However, since the hydroxyl groups of starch were consumed during the crosslinking reaction, both the peak intensity of $-\mathrm{OH}$ and $-\mathrm{OH}$...O- were reduced in c-PCS.

\subsubsection{SEM images}

Fig. 7 displays the SEM images of (a) corn starch, (b) PCS and (c-d) cPCS. By comparison, the c-PCS demonstrates much rougher surface

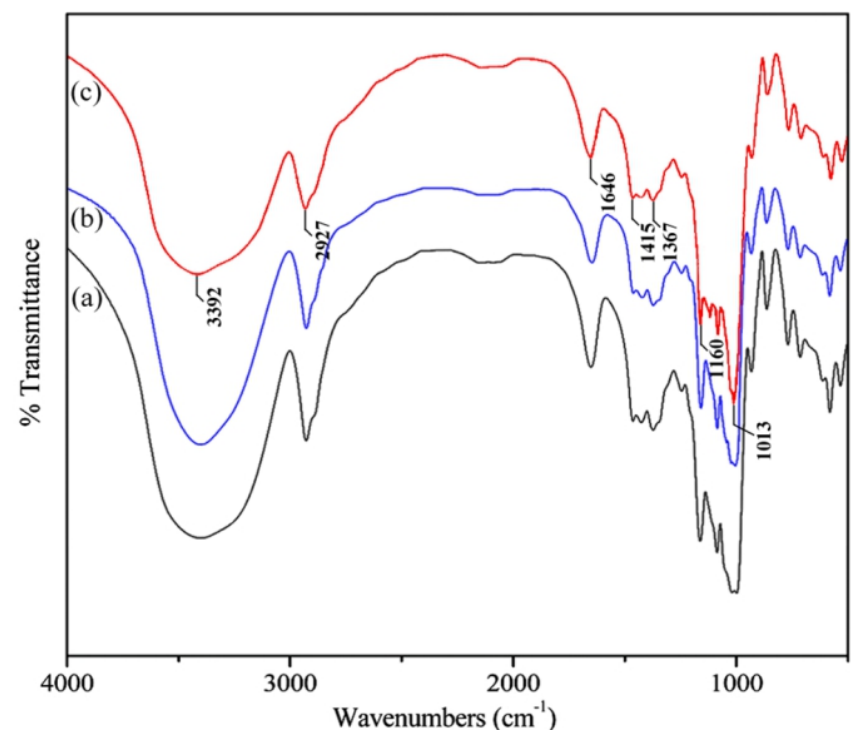

Fig. 6 The FTIR spectra of (a) corn starch, (b) PCS and (b) c-PCS.

than PCS and native corn starch. The reason is that the hydrolysis mainly occurred in the amorphous instead of the crystalline regions during the preparation of PCS using $\alpha$-amylase and glucoamylase. ${ }^{42}$ Thus, the crystallinity was increased as the hydrolysis proceeded. Correspondingly, the obtained PCS exhibited a relatively smooth surface if the hydrolysis was moderate. Different from hydrolysis, the cross-linking reactions bonded the starch molecules together and therefore interrupted the regularity of the chain, leading to a decreased crystallinity. ${ }^{43,44}$ Specifically, for amylose, i.e. the linear starch molecules, the chain linearity was damaged, and part of the crystalline region

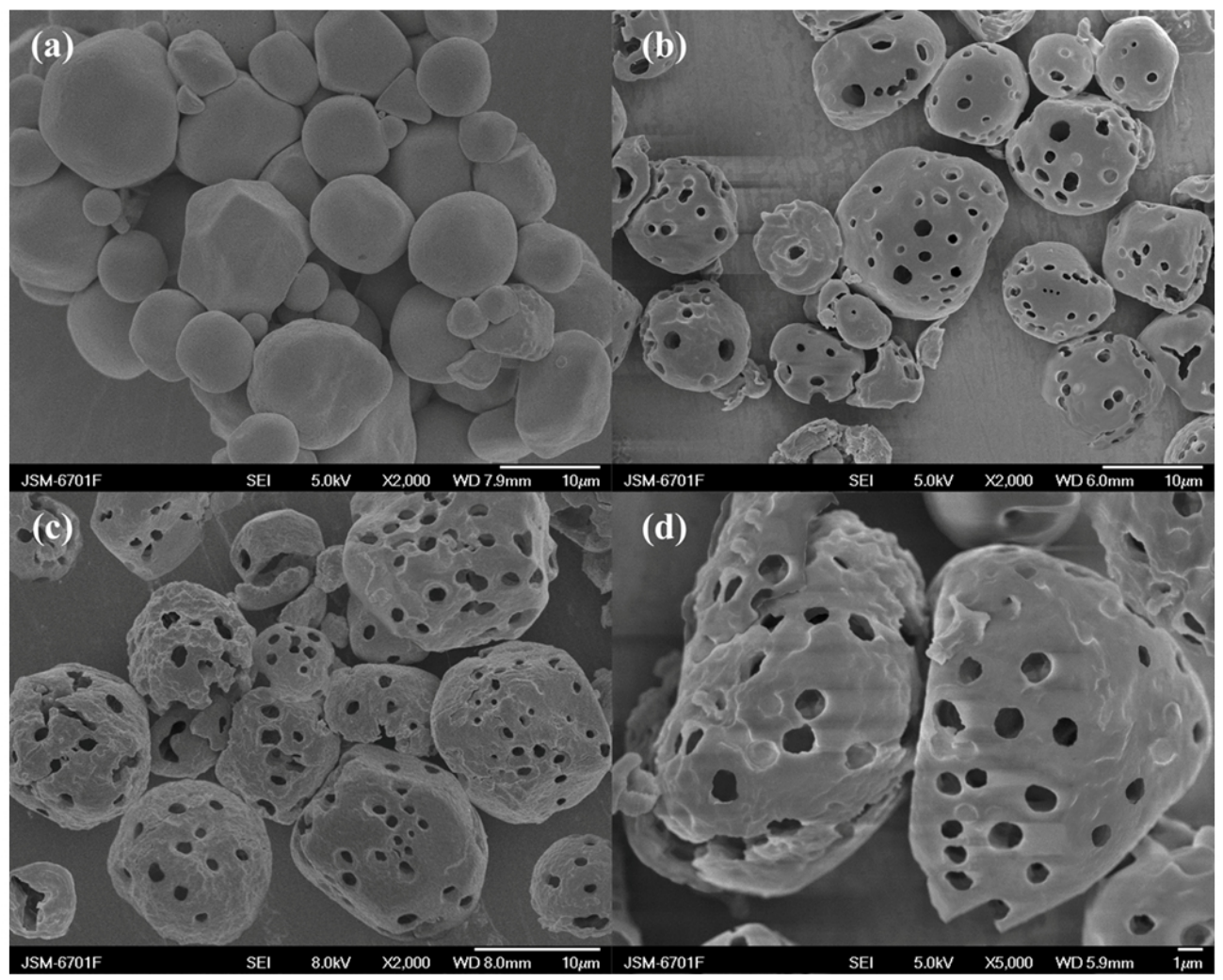

Fig. 7 SEM images of (a) corn starch, (b) PCS and (c-d) c-PCS. 
would be transformed into amorphous region. In regard to amylopectin, i.e. the branched starch molecules, the branches become much messier, and the resulted steric hindrance also reduced the crystallinity of starch molecules. The rougher surface of c-PCS compared to that of PCS is consistent with what was observed in cross-linked starch by other researchers. ${ }^{45}$ The roughness is beneficial for the adsorption and immobility of small molecules, and thus the c-PCS demonstrated higher adsorption ratio than PCS (48.3\% vs. 38.1\%).

\section{Conclusions}

c-PCS has been successfully prepared using a two-step approach, i.e., alkalization of PCS using $\mathrm{NaOH}$ with the aid of $\mathrm{NaCl}$, followed by the cross-linking reaction using ECH. Methyl violet was employed as an adsorbed model to investigate the effect of experimental parameters on the adsorption capability of the as-obtained c-PCS. Alkalization was favorable for the following cross-linking reaction; nevertheless, care must be taken to control the amount of $\mathrm{NaOH}$, the alkalization temperature, and the alkalization time, which could give rise to undesirable gelatinization of PCS. In the case of the cross-linking reaction, the amount of $\mathrm{ECH}$, the solution volume, $\mathrm{pH}$ value, the reaction temperature and time exhibited varying effects on the adsorption properties of c-PCS. The optimum parameters were obtained as follows: $m_{\text {NaOH }} / m_{\mathrm{pcs}}=0.02, m_{\mathrm{NaCl}} / m_{\mathrm{pcs}}=0.06, T_{\mathrm{a}}=40{ }^{\circ} \mathrm{C}, t_{\mathrm{a}}=1.0 \mathrm{~h}$, $V_{\mathrm{ECH}} / m_{\mathrm{pcs}}=0.003(\mathrm{~mL} / \mathrm{g}), V_{\mathrm{s}} / m_{\mathrm{pcs}}=7(\mathrm{~mL} / \mathrm{g}), \mathrm{pH}=10, T_{\mathrm{c}}=20{ }^{\circ} \mathrm{C}, t_{c}=3.0$ h. The as-obtained c-PCS displayed much rougher surface and demonstrated a higher adsorption ratio of methyl violet compared with the pristine PCS (48.3\% vs. $38.1 \%)$. The robust, non-toxic, and environmental friendly c-PCS with high adsorption capability is expected to find promising applications as sustainable adsorbents in many fields.

\section{Acknowledgement}

This work is financially supported by Natural Science Foundation of Tianjin City (16JCYBJC42700), National Natural Science Foundation of China (51703162), Tianjin Municipal Education Commission (2017KJ016), Technology Foundation for Selected Overseas Chinese Scholar (201801), and Youth Innovation Foundation of Tianjin University of Science and Technology (2015LG01).

\section{References}

1. I. J. Bradshaw and J. F. Kennedy, Polym. Int., 2010, 17, 377-378.

2. F. Miculescu, A. Maidaniuc, S. I. Voicu, V. K. Thakur, G. E. Stan and L. T. Ciocan, ACS Sustain. Chem. Eng., 2017, 5, 8491-8512.

3. J. R. Kim and A. N. Netravali, Polymer, 2017, 117, 150-159.

4. G. Coativy, B. Pontoire, D. Lourdin and E. Leroy, Polymer, 2015, 77, 361365 .

5. B. Sancey, J. Charles, G. Trunfio, P.-M. Badot, M. Jacquot, X. Hutinet, S. Gavoille and C. grégorio, Ind. Eng. Chem. Res., 2011, 50, 1749-1756.

6. T. Ghosh Dastidar and A. Netravali, ACS Sustain. Chem. Eng., 2013, 1, 15371544

7. J. Ji, J. Li, J. Qiu and X. Li, Sep. Purif. Technol., 2014, 131, 1-7.

8. D. Cui, M. Liu, B. Zhang, H. Gong and Y. Bi, Starch - Stärke, 2011, 63, 354-363.

9. D. Cui, M. Liu, R. Liang and Y. Bi, Starch - Starke, 2007, 59, 91-98.

10. D. Cui, M. Liu, L. Wu and Y. Bi, Int. J. Biol. Macromol., 2009, 44, 294-299.
11. X. Hu, C. Liu, Z. Jin and Y. Tian, Sep. Purif. Technol., 2015, 151, 201-210.

12. A. Dura, W. Błaszczak and C. M. Rosell, Carbohydr. Polym., 2014, 101, 837-845.

13. Y. Benavent-Gil and C. M. Rosell, Carbohydr. Polym., 2017, 157, 533-540.

14. K. Chauhan, J. Kaur, P. Singh, P. Sharma, P. Sharma and G. S. Chauhan, Ind. Eng. Chem. Res., 2016, 55, 2507-2519.

15. E. Xu, Z. Wu, J. Long, A. Jiao, and Z. Jin, ACS Sustain. Chem. Eng., 2018, 6, $9572-9578$.

16. G. M. Glenn, A. P. Klamczynski, D. F. Woods, B. S. Chiou, W. J. Orts and S. H. Imam, J. Agr. Food. Chem., 2010, 58, 4180-4184.

17.D.Wu, A.Samanta, R. K. Srivastava and M. Hakkarainen, Biomacromolecules, 2017, 18, 1582-1591.

18. L. Xu, G. Chen, C. Peng, H. Qiao, F. Ke, R. Hou, D. Li, H. Cai and X. Wan, Carbohydr. Polym., 2017, 160, 82-89.

19. X. Liang, C. Li and C. Qi, J. Mater. Sci., 2011, 46, 5345-5349.

20. X. Wang, Y. Yuan and T. Yue, Starch - Starke, 2014, 67, 225-236.

21. D. J. Gallant, B. Bouchet and P. M. Baldwin, Carbohydr. Polym., 1997, 32, 177-191.

22. P. R. Chang, D. Qian, D. P. Anderson and X. Ma, Carbohydr. Polym., 2012, $\mathbf{8 8}, 604-608$.

23. F. G. Torres, A. R. Boccaccini and O. P. Troncoso, J. Appl. Polym. Sci., 2007, 103, 1332-1339.

24. J. Zheng, Q. Li, A. Hu, L. Yang, J. Lu, X. Zhang and Q. Lin, Starch - Stärke, 2013, 65, 621-627.

25. J. Y. Kim, K. C. Huber, Carbohydr. Polym., 2013, 91, 39-47.

26. Z. Li, L. Cai, Z. Gu and Y.-C. Shi, J. Agr. Food. Chem., 2014, 62, $8114-$ 8119 .

27. N. S. Yussof, U. Utra and A. K. Alias, Starch - Starke, 2013, 65, 285-295.

28. S. Naguleswaran, J. Li, T. Vasanthan, D. Bressler and R. Hoover, Carbohydr. Polym., 2012, 88, 864-874.

29. B. Zhang, D. Cui, M. Liu, H. Gong, Y. Huang and F. Han, Int. J. Biol. Macromol., 2012, 50, 250-256.

30. F. Gao, D. Li, C. Bi, Z. Mao and B. Adhikari, Carbohydr. Polym., 2014, 103, 310-318

31. H. Xu, H. Canisag, B. Mu and Y. Yang, ACS Sustain. Chem. Eng., 2015, 3, 2631-2639.

32. D. Cui, Study on the Preparation and Application of Microporous Starch, Crosslinked Microporous Starch and Crosslinked Microporous Starch Microspheres. Lanzhou University, 2010.

33. A. A. Ragheb, I. Abdel Thalouth and S. Tawfik, Starch - Starke, 1995, 47, 338-345.

34. S. A. Roberts and R. E. Cameron, Carbohydr. Polym., 2002, 50, 133-143.

35. P. Chinachoti, M. L. Kimshin, F. Mari and L. Lo, J. Hand Surg., 1991, 5, 537-543.

36. A. N. Jyothi, K. Sasikiran, M. S. Sajeev, R. Revamma and S. N. Moorthy, Starch - Stärke, 2005, 57, 547-555.

37.T. Baks, M. E. Bruins, A. E. M. Janssen and R. M. Boom, Biomacromolecules, 2008, 9, 296-304.

38. Đ. Ačkar, J. Babic', D. Šubaric', M. Kopjar and B. Miličevic', Carbohydr. Polym., 2010, 81, 76-82.

39. L. K. C. Sc, R. H. M. Chairman, Starch - Stärke, 2010, 24, 110-116.

40. M. A. Horianski, J. M. Peralta and L. A. Brumovsky, Nutr. Food. Sci., 2016, 46, 517-528.

41. O. S. Kittipongpatana and N. Kittipongpatana, Food Chem., 2013, 141, 1438-1444.

42. Y. Chen, S. Huang, Z. Tang, X. Chen and Z. Zhang, Carbohydr. Polym., $2011, \mathbf{8 5}, 272-275$

43. J. B. Hirsch and J. L. Kokini, Cereal. Chem., 2002, 79, 102-107.

44. P. Ispas-Szabo, F. Ravenelle, I. Hassan, M. Preda and M. A. Mateescu, Carbohyd. Res., 1999, 323, 163-175.

45. S. H. Koo, K. Y. Lee and H. G. Lee, Food Hydrocolloid., 2010, 24, 619-625. 